ARTIGO ORIGINAL

\title{
IMPORTÂNCIA DO GERENCIAMENTO COLORIMÉTRICO NA CERÂMICA
}

\author{
Lucas Correa, Solange S. Bianchini \\ Faculdade SATC, Graduação em Design, Criciúma, SC, Brasil \\ E-mail: solange.bianchini@satc.edu.br
}

\section{Resumo:}

O gerenciamento de cor nas peças cerâmicas é importante, principalmente no momento em que o comprador avalia o produto. A indústria cerâmica por vezes apresenta dificuldades em desenvolver perfis de cores os quais podem ser aplicados de forma eficiente em suas peças, pois existem múltiplos fatores que influenciam variações tonais, assim, por meio desse projeto busca-se um estudo do gerenciamento de cores, no qual possa auxiliar os profissionais que atuam na área de design gráfico. Como principal objetivo desse trabalho pretende-se realizar um estudo de gerenciamento colorimétrico e sobre os elementos influenciadores na variação de cor através do processo cerâmico, desde a etapa da esmaltação até o final do ciclo de queima. Para tanto a pesquisa será quali-quantitativa e de caráter aplicado, fundamenta-se o trabalho com uma pesquisa bibliográfica sobre 0 gerenciamento de cores e sua importância no meio cerâmico, algumas ferramentas utilizadas para leitura colorimétrica, softwares de criação de perfis ICC, a aplicação de métodos de desenvolvimento de perfis e análise de dados obtidos após a utilização de cada perfil experimental.

Palavras-chave: Cerâmica. Perfil de cor. Colorimetria. Impressão digital.

\section{Introdução}

A impressão digital, tem sido muito importante em diversos segmentos, e no setor cerâmico vem se destacando e se desenvolvendo. Assim a colorimetria bem como os elementos na variação de cor em um processo cerâmico são demasiados importantes, além disso, o uso de ferramentas utilizadas para leitura colorimétrica, softwares de criação de perfis ICC, e a aplicação de métodos de desenvolvimento tornam-se importantes na realização de uma peça.

Sob esse aspecto, Hutchings (2010) destaca que: A impressão digital teve uma grande expansão no setor cerâmico a partir de 2008 com a popularização das impressoras a jato de tinta para o seguimento, o que causou uma revolução na indústria. Por ser um processo mais rápido e eficaz em relação a outros métodos de impressão que utilizam telas planas, serigráficas rotativas ou rotocolor com rolo de silicone (a chamada impressão direta). Com a expansão desse tipo de impressão, faz-se importante o estudo do processo de fabricação do material a ser impresso, e o gerenciamento de cores para garantir constância e qualidade no produto final.

De acordo com Ambrose e Harris (2009), a cor é um dos primeiros elementos registrados ao observar um objeto, e um dos principais elementos do Design Gráfico. O revestimento cerâmico é um produto de Design, e a cor é uma importante característica desses produtos. Neste seguimento industrial são encontrados problemas relacionados às dificuldades em manter constância nas tonalidades dos produtos em determinados espaços de tempo, uma vez que a cor é afetada por inúmeras variáveis do processo fabril, tal como tipologia do esmalte, variações ocorrentes neste insumo, como camada aplicada, temperatura e ciclo de queima, além 
de próprias variações ocorrentes durante a aplicação da impressão digital, como entupimento dos bicos. Desta maneira, o objetivo geral desse projeto é identificar, por meio de provas de impressão, os agentes causadores dessas variações e como o gerenciamento adequado pode trazer qualidade e regularidade tonal no produto cerâmico. Para almejar o objetivo geral, destacam-se outros objetivos, como:

- Buscar referências sobre a importância do gerenciamento de cores;

- Analisar os fatores influenciadores na cor;

- Realizar testes de impressão;

A pesquisa é de caráter aplicado, e quanto à abordagem do problema a pesquisa é de caráter quali-quantitativo.

\section{FUNDAMENTAÇÃO TEÓRICA}

\subsection{Importância do Gerenciamento Colorimétrico na Cerâmica}

As cores e seus aspectos colorimétricos são importantes nas peças cerâmicas, o trabalho de gerenciamento colorimétrico precisa ser de qualidade, muitas vezes o comprador optará pela qualidade do produto, avaliando a cor das peças. Além disso, a variação de tonalidade do ponto de vista do negócio, propicia a abertura de pequenos lotes de produtos, que em geral apresentam maior dificuldade de comercialização, pois os clientes prezam por lotes amplos e homogêneos.

De acordo com esse ponto de vista, alguns estudiosos destacam que, as cores vistas em uma etapa do processo raramente correspondem à coloração observada em outras etapas. Essa inerente falta de correspondência visual da cor torna difícil prever os resultados do impresso final, tornando necessária uma forma de se gerenciar as cores. (DACOREGIO 2016, p. 12-13 apud KING; SHARMA, 2002).

\subsubsection{Cor}

O mundo é colorido, um emaranhado de cores. No design, a cor é essencial, em uma propaganda, por exemplo, as cores têm como requisito chamar a atenção. Para Ambrose e Harris (2009) a forma mais imediata de comunicação não verbal é a cor e um dos principais meios para expressar uma ideia ou passar uma mensagem.

Desta maneira, para o entendimento do gerenciamento de cor na cerâmica, faz-se necessário o entendimento da cor como fenômeno físico e sensação fisiológica, como apontava Newton (1672) em seus estudos sobre a óptica. Segundo ele, as cores apenas se tornam visíveis por meio do processo de separação por refração da luz.

Assim como explica Yamane (2008), a cor só existe se houver luz, é um fenômeno físico, ou seja, apenas se torna cor quando passa por uma curva de onda onde gera seu espectro. Já Pedrosa (2003), destaca que a cor é apenas uma sensação provocada pela ação da luz sobre o órgão da visão. Portanto, entende-se que a cor é uma percepção do cérebro produzida pela radiação eletromagnética emitida por um corpo.

A retina possui células especiais chamadas de bastonetes e cones. Estes são células sensíveis à luz. Os cones possuem elementos químicos que reagem à luz, chamados de fotopigmentos o que torna cada cone sensível a um determinado comprimento de onda de cor luz (vermelho, verde e azul). (BUENO, 2015)

Com isso, a atuação das cores em produtos gráficos ou em qualquer objeto é obtida pela síntese aditiva e subtrativa de cores. O estudioso Harris (2009) explica que a síntese aditiva é derivada de três fontes de luz distintas: vermelho, azul e verde (sistema RGB), que sobrepostas geram outras cores: amarelo (derivado de vermelho e verde), o ciano (derivado de verde e azul) e o magenta (derivado de azul e vermelho). A sobreposição de todas as cores, procedimento contrário da decomposição gera o branco. Sobre o sistema aditivo nota-se a teoria na figura 1 . 


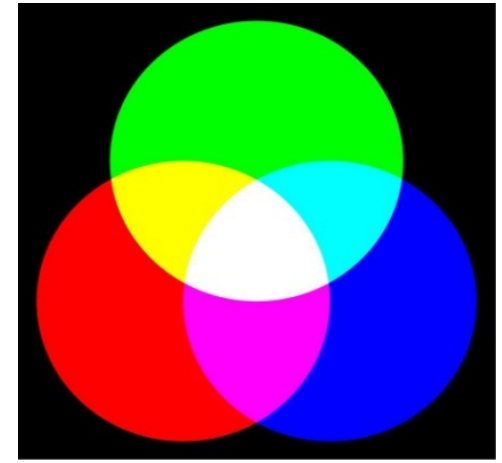

Figura 1 - Sistema Aditivo. Fonte: https:umpoucosobrecor.

Sobre a síntese subtrativa, Harris (2009) afirma que elas são o resultado de uma junção das cores: ciano e magenta, juntas formando o azul; o resultado da combinação entre amarelo e magenta é a cor vermelho; e o verde por meio da mistura de ciano e amarelo. Com a junção das cores azul, magenta e ciano se obtêm a cor preta como demonstra-se na figura 2.

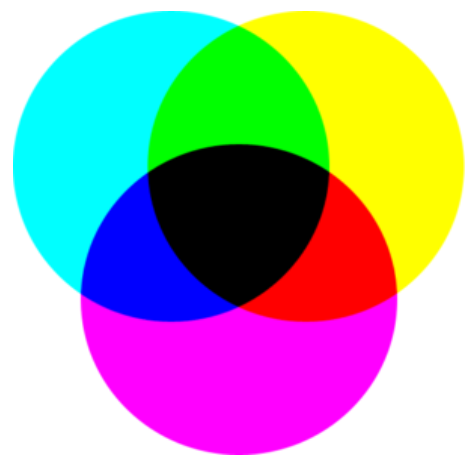

Figura 2 - Sistema Subtrativo. Fonte:https: umpoucosobrecor.wordpress.com

Ainda, sob essa perspectiva Dacoregio (2016) destaca que o entendimento dos sistemas aditivos e subtrativos, são importantes para a compreensão de todo processo de impressão. Para o autor, com o estudo do gerenciamento colorimétrico, são imprescindíveis conhecimentos sobre os meios de reprodução de cor em seu devido espaço, tanto na reprodução de cor luz proporcionada em forma de monitores e scanners, quanto à representação com base em pigmentos que é vista em todos os tipos de impressos. Assim, as duas formas são amplamente utilizadas no processo de impressão.

Sobre esse estudo Dacoregio (2016) ressalta que os monitores emitem luz, vermelha, verde e azul, (RGB), onde se pode distinguir a frequência luminosa das mesmas. Nos impressos o autor diz que temos a chamada cor pigmento, que se assemelha muito ao sistema subtrativo de refração luminosa. Para ele, a cor pigmento é composta pelas cores primárias: ciano (C), magenta $(\mathrm{M})$, amarelo $(\mathrm{Y})$ e a cor chave $(\mathrm{K})$, que seria a cor preta. (DACOREGIO 2016, p. 19-20 apud COPETTI 2013)

As cores correspondem às três cores tricromáticas, produzidas pelo processo de separação de cores necessárias para a reprodução das imagens coloridas mais o preto. O preto é representado pela letra "K", que significa "Key" (chave). Quase todas as cores podem ser impressas com uma combinação dessas cores subtrativas em um processo de impressão em quadricromia. (HARRIS, 2009, p. 32)

Bueno (2015), afirma que as impressoras gráficas que utilizam o sistema CMYK, usam três cores básicas complementares e a combinação delas resulta na cor preta, sendo essa acrescentada à parte para deixar o sistema mais eficiente. Destaca ainda, que, como os monitores utilizam o sistema aditivo (RGB) e os sistemas 
de impressão utilizam o sistema CMYK, é indispensável à conversão do arquivo de RGB para CMYK para que as cores sejam lidas de forma apropriada pela impressora.

Para garantir uma impressão fiel ao design concebido, são necessários esses conhecimentos sobre cor para que seja aplicada de forma adequada na impressão digital cerâmica.

\subsubsection{Colorimetria}

De acordo com Lopes (2009), colorimetria é a ciência e tecnologia usada para quantificar e descrever por meio de modelos matemáticos, a percepção humana da cor.

Por se tratar da percepção humana, a identificação e diferenciação de cor se faz diferente em cada observador. Com isso a CIE (Commission Internationale de L'Eclairage, Comissão internacional de Iluminação), estabelece em 1931, o diagrama cromático Yxy. figura 3 (MELCHIADES; BOSCHI, 1999)

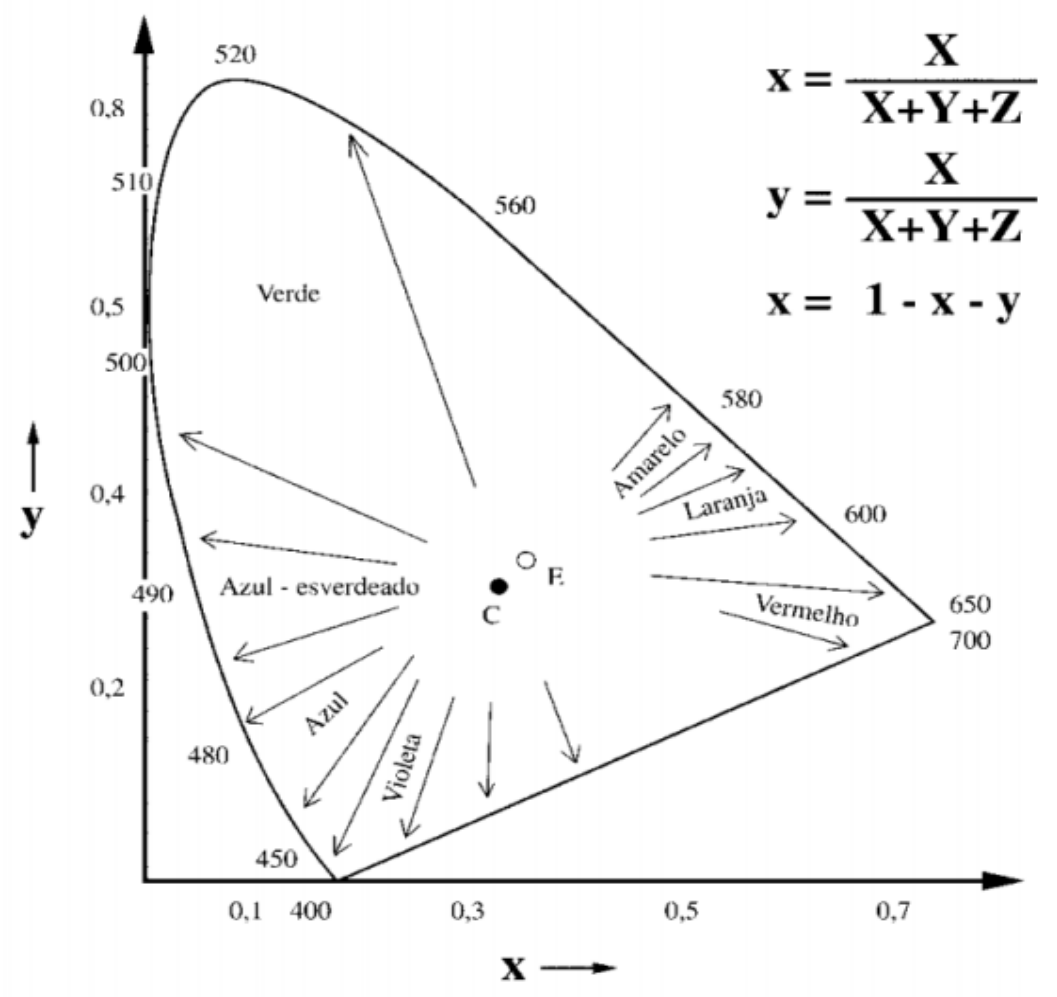

Figura 3 - CIE Yxy. Fonte:<http://www.ceramicaindustrial.org.br/

O sistema CIE define três fatores para existência da cor, o iluminante, o objeto e o observador. Com a determinação triestímulos do observador padrão, que em composição com a distribuição espectral (SPD) do iluminante e com a curva de refletância do objeto, permite-se transformar essa percepção do observador padrão em um valor numérico, essa representação chama-se CIE XYZ. Nesse sistema as funções triestímulos são representadas baseadas nas cores primárias X (vermelho), Y (verde) e Z (azul) demonstradas na figura 4. (LOPES, 2009) 


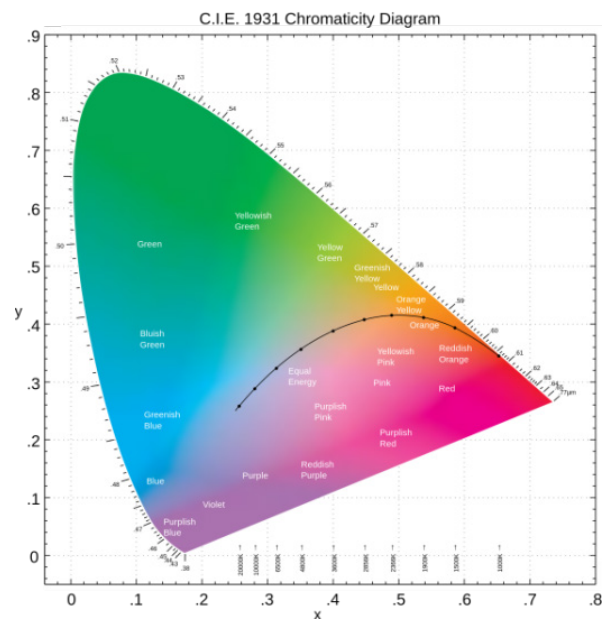

Figura 4 - CIE XYZ. Fonte: LOPES, 2009.

Esse sistema pode apresentar problemas devido à proximidade de algumas cores, o que dificulta a sua diferenciação. De acordo com Leão (2005), com isso o modelo de espaço de cores CIELAB foi desenvolvido, nesse sistema o valor de luminosidade $L^{*}$ é o valor aproximado da luminância $Y$ (para o CIE Yxy), variando de branco (100) a preto (0), o valor de $\mathrm{a}^{*}$ pode variar de verde a vermelho, e o valor de $\mathrm{b}^{*}$ varia de azul a amarelo; de forma análoga à percepção das cores pelo cérebro, ou seja, cores-opostas, como se pode observar na figura 5 .

Ainda, conforme aponta em seu estudo Vanderlind e Faraco (2017), atualmente o sistema CIELAB é o mais utilizado entre os modelos de espaço de cor. Este sistema é amplamente utilizado porque correlacionam de forma consistente os valores de cor com a percepção visual, como nota-se também na figura 5 .

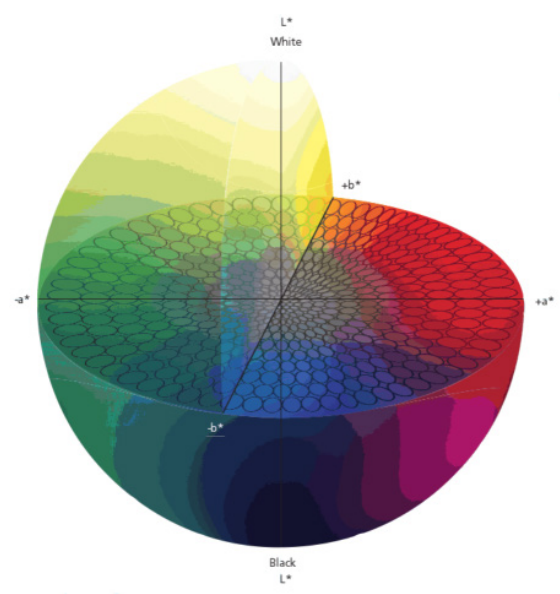

Figura 5 - CIELAB. Fonte: LEÃO, 2005

Desta forma, a compreensão desse sistema é importante, pois a análise e discussão dos resultados deste artigo serão feitas utilizando essa ferramenta, por ser o mais difundido. Encerrando essa etapa do estudo inicia-se o estudo sobre o revestimento cerâmico.

\subsection{Revestimento Cerâmico e seu processo de fabricação}

O revestimento cerâmico é utilizado para revestir chão e paredes e está presente no dia-a-dia de muitas pessoas. Com o desenvolvimento de tecnologias de decoração, os revestimentos passaram a ser desejo de consumo, e tornaram-se parte da decoração, sendo aplicados em qualquer local. Assim, as peças cerâmicas podem ser encontradas em vários imóveis, desde casas a instalações comerciais. 
Ferrari e outros estudiosos destacam que a cerâmica define-se como todo o material composto por matérias primas inorgânicas sejam estas naturais ou sintéticas, que de um estado de pó por meio de um processo químico envolvendo queima, torna-se sólido, que possui composição parcialmente cristalina ou vítrea. (FERRARI et al., 2000)

De acordo com Raulino (2012, p. 17) essa crescente evolução, principalmente das indústrias, permite que hoje sejam produzidas cerâmicas com tecnologias cada vez mais avançadas. Ainda, para o autor em nosso país pode-se afirmar que o segmento de revestimentos é um dos principais da indústria brasileira, pois esse setor possui tecnologia e processos avançados de produção, e vem se destacando no âmbito mundial. (2012, p. 18-19)

Portanto as indústrias de revestimentos cerâmicos possuem um grande desenvolvimento, pois atendem diversas especificidades, além de evoluírem conforme suas necessidades.

A produção de placas de revestimentos cerâmicos é um procedimento físico-químico que faz com que os produtos adquiram as propriedades úteis desejadas: absorção, dureza, cor entre outras. (COELHO, 1996 apud FERRARI et al. 2000). De acordo com esse ponto de vista, Raulino (2012, p 17) destaca que a cerâmica é considerada uma atividade de produção de artefatos, em que o principal componente seria a argila, pois se torna fácil de moldar quando umedecida.

Para a Associação Brasileira de Cerâmica (2018), em síntese, os materiais cerâmicos são compostos de duas ou mais matérias-primas e aditivos como água, dois ou mais tipos de argilas com características distintas entram em sua composição. Os revestimentos cerâmicos são divididos em várias categorias, conforme suas características técnicas, como: azulejo, pastilha, porcelanato, grês lajota, louças e isoladores elétricos. (RAULINO, 2012, p. 19)

O processo de fabricação cerâmica é explicado por Vanderlind e Faraco (2017), em etapas: dosagem, moagem, atomização (opcional), conformação, secagem, decoração, tratamento térmico, classificação e expedição.

1. Dosagem: As matérias primas são dosadas de acordo com a fórmula;

2. Moagem: Processo de homogeneização e diminuição granulométrica, por meio de moinhos;

3. Atomização: Utilizado apenas se a moagem foi feita com adição de água, serve para secagem da matéria prima, transforma-a em pó atomizado;

4. Conformação: Etapa que o pó atomizado ganha forma de placa cerâmica, compactado por prensas;

5. Secagem: Após a conformação, é realizada uma nova secagem; para retirada da umidade residual do pó, necessária para o processo de conformação

6. Decoração: São aplicados o engobe e o esmalte e variadas técnicas de decoração, como a impressão digital;

7. Tratamento Térmico: Comumente conhecida como queima, nessa etapa o revestimento passa por transformações físico-químicas, nas quais adquire as características projetadas, como: dimensões, cor, resistência mecânica entre outras;

8. Classificação: Escolha das peças por meio de parâmetros pré-definidos;

9. Expedição: Etapa na qual o produto cerâmico é expedido da indústria para o cliente;

Entre os estágios da fabricação de revestimentos cerâmicos, a decoração é um dos mais importantes, nesta etapa as principais características do design serão aplicadas, bem como os vidrados e a impressão digital, etapas foco do estudo, contudo outras etapas do processo influenciam no produto final, como a queima, por exemplo. (COELHO, 1996 apud FERRARI et al. 2000).

Sob essa perspectiva, referente às características da decoração e as tecnologias utilizadas nessa etapa no revestimento cerâmico, Raulino (2012) apud Neumaier e Horn (s/d) relatam alguns tipos como a decoração a seco na qual os pigmentos são aplicados na massa durante o processo de conformação; já na decoração por 
decalcomania, os autores destacam que essa é uma decoração indireta, na qual se reproduz a imagem sobre uma base. E na serigrafia, essa técnica de decoração em contato direto com a peça.

Ainda, o autor cita que na técnica de incisão a laser e rolo de silicone: trata-se da utilização de cilindros de silicone com incisão a laser, tendo assim maior precisão e definição de imagens. No tipo de decoração Vertical Dry: esta é caracterizada pela decoração sem contato, tratando-se de uma aplicação de baixa camada de esmalte a seco. (RAULINO, 2012)

\subsubsection{Revestimento e decoração}

A Associação Brasileira de Cerâmica (2018) ressalta que muitos artefatos cerâmicos, como louça sanitária, louça de mesa, isoladores elétricos, materiais de revestimento e outros, recebem uma camada fina e contínua de um material denominado de esmalte ou vidrado, que após a queima adquire o aspecto vítreo. Esta camada vítrea contribui para os aspectos estéticos, higiênicos e melhoria de algumas propriedades como a mecânica e a elétrica. Muitos materiais também são submetidos a uma decoração, a qual pode ser feita por diversos métodos, como serigrafia, decalcomania, pincel e outros. Neste caso são utilizadas tintas que adquirem suas características finais após a queima das peças. (ASSOCIAÇÃO BRASILEIRA DE CERÂMICA, 2018).

Nesta etapa do processo cerâmico são aplicados os chamados vidrados. Conforme aponta Abril Filho (1999), existem vários tipos de vidrados cerâmicos e a escolha entre eles depende do resultado esperado. Os mais comuns utilizados na indústria cerâmica são: os engobes e vidrados que enquanto barbotina são chamados de esmaltados.

\subsubsection{Engobes}

O engobe cerâmico é interface entre a peça cerâmica e o esmalte, empregado para impedir problemas devido à porosidade e deformações da peça cerâmica, facilita a adesão do esmalte, impossibilita a formação de curvatura, gretamento e descolamento, forma um substrato branco opaco ou colorido conforme sua formulação que permite o desenvolvimento ideal dos esmaltes. (DAL BÓ, 2012, p. 118)

Para Abril Filho (1999, p. 40) o engobe é principalmente utilizado no processo de mono-queima, com o objetivo de minimizar defeitos provenientes da massa, proporcionar um bom acordo massa-vidrado e também uniformizar a cor de fundo, ocultando a cor do suporte que em geral é escura, o que desfavorece a decoração do revestimento.

\subsubsection{Vidrados ou Esmaltes}

Atualmente na produção de revestimentos cerâmicos o meio de decoração mais utilizado é a aplicação de esmaltes ou vidrados. Flores (2018) afirma que os vidrados podem ser classificados quanto à transparência: transparentes, translúcidos ou opacos. Quanto ao brilho: brilhante, acetinado ou mate.

Para a Associação Brasileira de Cerâmica (2018) os esmaltes (vidrados) são arranjados a partir de matérias-primas naturais e de produtos da indústria química. De acordo com a associação, entre as matérias-primas naturais e químicos utilizadas:

Dentre as matérias-primas naturais estão o quartzo, areia do mar, quartzito, caulim, lepidolita, espodumênio, ambligorita, feldspato, calcita, fluorita, talco, dolomita e zirconita. Já entre os produtos químicos podem ser encontrados o borax, ácido bórico, carbonato de sódio, nitrato de sódio, carbonato de potássio, nitrato de potássio, óxidos de chumbo, carbonato de cálcio, carbonato de bário, carbonato de magnésio, carbonato de lítio, carbonato de estrôncio e óxido de zinco. (ASSOCIAÇÃO BRASILEIRA DE CERÂMICA, 2018) 
O vidrado ou esmalte pode ser compreendido como um vidro com a finalidade cobrir determinada superfície: seja cerâmica, metal ou outro vidro. Seu estado normal é transparente, incolor, podendo ser modificado para opaco e colorido por meios de óxidos opacificadores e colorantes. (FLORES, 2018)

Sobre a aplicação dos vidrados e sua influência na tonalidade Abril Filho (1999, p. 41) destaca que os efeitos são menos aparentes. Porém o problema poderá ocorrer na função da camada de vidrado aplicado sobre a peça, variando basicamente em função da densidade e da viscosidade. Ainda de acordo com o autor a forma utilizada para o controle da camada aplicada é por meio da determinação do peso de vidrado aplicado sobre a peça.

\subsubsection{Impressão Digital}

A impressão digital é definida por Lopes (2009) et al. como qualquer registro sobre papel, ou outro suporte, feito por equipamentos de impressão. As informações para impressão são recebidas de um computador em forma de dados digitais em sequência ordenada de "zeros e uns", sem a necessidade da confecção de matrizes permanentes para transferência direta desses dados.

Em uma definição de Mortara (2009), impressão digital é todo tipo de "impressão sem fôrma". A fôrma é o objeto que conduz a imagem ao suporte por meio de contato físico. Na impressão digital a "fôrma" é virtual e temporária em forma de cargas eletrostáticas.

As principais tecnologias de impressão digital de acordo com Mortara (2009) são: Eletrografia e Jato de Tinta. Eletrografia pode ser dividida em dois tipos: Toner Seco e Toner Líquido. A tecnologia de impressão a Jato de tinta tem dois formatos, o Drop on Demand (gota sob demanda), e Jato contínuo.

O jato de tinta contínuo é o mais usado para impressão em papel, no qual, utiliza princípios físicos, magnéticos e eletrostáticos. A imagem é convertida em uma informação virtual, em seguida cria-se um fluxo sucessivo de gotas carregadas proporcionalmente à posição que precisam ocupar na base a ser impressa. (REIG et al., 2012)

No jato de tinta sob demanda, como o próprio nome sugere, cada gota é gerada exatamente no tempo em que é requerida. É o mais utilizado em escala industrial, por ser mais preciso ter o menor tamanho de gota, e um número elevado de gotas por polegada (dpi). (REIG et al., 2012)

Nesta modalidade de impressão Mortara (2009) destaca que existem duas tecnologias para geração das gotas sob demanda, a térmica e a piezoelétrica. $\mathrm{O}$ autor ainda ressalta que a térmica desenvolvida por Hewlett Packard (HP) e Canon são tecnologias fundamentadas em calor. A câmara com tinta é aquecida até definida temperatura satisfatória para gerar uma bolha de gás, que por sua vez, expele a tinta pelo orifício da câmara, na direção do substrato. (MORTARA, 2009)

Conforme explica Mortara (2009), a tecnologia piezoelétrica desenvolvida pela Epson é baseada nos cristais piezelétricos, que por meio de suas propriedades, se deformam ao receber cargas elétricas. Assim como no processo térmico, a tinta fica armazenada em uma câmara, com a diferença que nesta modalidade uma das paredes é composta de cristal piezelétrico. Com a aplicação de uma carga elétrica é provocada uma diminuição do tamanho da câmara e a gotícula é expelida pelo orifício, em direção a base a ser impressa.

Como no procedimento de impressão térmico é imprescindível à vaporização de um volume de tinta, existem restrições sobre os materiais que podem ser ejetados pelo orifício por esse método; com isso as tintas devem ser voláteis. No método piezelétrico não existem restrições quanto à volatilidade da tinta. (HUTCHINGS, 2010)

Com o processo de impressão a Jato de Tinta descrito a cima, no capítulo seguinte, aponta-se a sua inserção no meio cerâmico. 


\subsection{Impressão Digital na Cerâmica}

O setor de revestimentos cerâmicos passou por grandes transformações em suas peças cerâmicas bem como a impressão de desenhos. Na última década de acordo com Cabedo, Zaragoza e Canósb (2014, p. 7) testemunhou-se a crescente, massiva implementação da tecnologia jato de tinta para decoração de placas cerâmicas.

Sob esse aspecto, com o ingresso da tecnologia nas indústrias, o antigo processo é modificado, segundo Reig et al. (2012), algumas vantagens para o setor de desenvolvimento e design devem ser evidenciadas:

Devido à divisão de tarefas entre o designer e o técnico em desenvolvimento, o designer torna-se essencial no contexto de criação. Deixa de desempenhar o trabalho de separação de cores, passando a dedicar-se na exploração de novas possibilidades estéticas. b) A separação de tintas passa a ser efetuada automaticamente, através de uma tecnologia de calibração e gestão de cores. (REIG et al., 2012)

Para facilitar o processo na produção das peças cerâmicas deu-se o início da utilização de máquinas de impressão digital agilizando esse setor na empresa. A decoração por jato de tinta de placas cerâmicas Cabedo, Zaragoza, e Canósb (2014, p. 12) destacam que só se tornou possível graças a um gerenciamento adequado ao longo de toda a cadeia de produção.

Para os autores esse tipo de tecnologia demorou, uma vez que mais de um século se passou entre uma e outra tecnologia, porém inovou a o setor de revestimentos cerâmicos, sendo que a última tecnologia ainda está em formação. (CABEDO, ZARAGOZA, E CANÓSB, 2014, p. 12). De acordo com essa ideia, sobre o trabalho na cerâmica industrial complementa-se que:

Até o momento, a utilização das técnicas convencionais de desenvolvimento de produto requeria um designer especializado em separação de tintas e um técnico especializado em efeitos e mistura de cores cerâmicas. Além disto, era necessária a realização de múltiplas provas em todas as fases (desenho, desenvolvimento, telas, cilindros etc.) até chegar ao protótipo final. Como consequência de tudo gerava-se um elevado custo em horas de pessoal e materiais, aspecto pouco otimizado até então. (REIG et al, 2012, p. 23)

De acordo com o Instituto de Tecnologia de Cerâmica, este destaca que o primeiro protótipo de impressora a Jato de Tinta para cerâmica surgiu no ano 2000 na feira Cevisama (feira anual de cerâmica, realizada na cidade de Valencia Espanha), apresentado pela empresa Kerajet. (CERÂMICA 2012)

A introdução desse tipo de máquina no setor tornou de suma importância o papel do designer como afirma Reig et al. (2012), às técnicas convencionais de desenvolvimento requeriam um designer especializado em separação de cores e um técnico especializado em efeitos e mistura de cores cerâmicas. Com isso, faziam-se necessários vários testes em todas as fases do processo de criação (desenho, desenvolvimento, telas, cilindros etc.) até chegar ao produto final. Consequentemente gerava-se um elevado custo em horas de pessoal e materiais.

Conforme apontado por Cristiano, Nandi e Zaccaron (2015), o sistema de decoração mais difundido na cerâmica é o sistema rotocolor (impressão com contato, através de rolos), contudo, apresenta limitações, as quais interferem na qualidade do impresso. Sendo assim, como alternativa de técnica impressão, as empresas do segmento vem se adaptando ao novo processo de impressão a jato de tinta, para decoração das suas placas cerâmicas.

Referente às tintas na decoração em revestimentos, esta devem satisfazer pelo menos duas finalidades importantes: podem ser impressas e apresentar as cores finais desejadas após a aplicação sobre o revestimento submetido ao processo de queima. (RAULINO, 2012, p. 24)

Existe uma limitação em relação as tintas utilizadas no processo de impressão digital na cerâmica. Em seu processo de fabricação são aplicadas altas temperaturas, com isso não é possível a utilização de pigmentos 
orgânicos, logo são utilizadas tintas pigmentadas a base de pigmentos inorgânicos. Estes pigmentos inorgânicos não alcançam as cores do modelo CMYK, composto por: ciano, magenta, amarelo e preto, ao invés dessas cores na cerâmica geralmente são utilizadas as cores: azul, marrom, bege e preto, advindas de pigmentos inorgânicos. (BOSCHI et al., 2016)

A impressão inkjet (ou jato de tinta) é um método de deposição de tinta sem contato, diferente dos métodos serigráficos e a rolo que exigiam contato físico com a peça a ser aplicada. Existem dois métodos de aporte de tinta, o jato contínuo e o de tinta sob demanda. Sobre o jato de tinta contínuo (REIG et al, 2012, p. 20) destaca que é o mais utilizado para impressão em papel, de acordo com o autor este tipo de impressão:

(...) Utiliza princípios físicos, magnéticos e eletrostáticos. A informação da imagem é convertida em uma imagem latente e posteriormente cria-se um fluxo contínuo de gotas carregadas proporcionalmente à posição que devem ocupar no substrato. (REIG et al, 2012, p. 20)

Ainda sobre o uso de máquinas de impressão digital, de acordo com Reig et al (2012), a inserção desse tipo de máquina no setor tornou-se de suma importância à gestão de cor, perfis e quadricromia, advindos do tradicional setor de artes gráficas, agora são mesclados com termos como multicanal, tintas, cerâmicas, vidrados de base e temperatura do forno, típicos da cerâmica.

Após o surgimento da tecnologia digital de injeção de tinta cerâmica, pouco a pouco a gestão de cor tornou-se importante até converter-se imprescindível em qualquer fluxo de trabalho. Em primeiro lugar, devem ser feitas calibrações e perfis de todos os elementos que intervêm na visualização e produção da cor: as ferramentas de digitalização (câmeras digitais ou scanner), os dispositivos de visualização (telas de computador) e as próprias máquinas de impressão. (CLAUSELL, ORTIZ E MIRA, 2012, p. 7)

No jato de tinta sob demanda, como o próprio nome sugere, cada gota é gerada exatamente no momento em que é requerida. É o mais utilizado em escala industrial, por ser mais preciso ter o menor tamanho de gota, e um número elevado de gotas por polegada (dpi).

Desta forma, com a probabilidade de novas resoluções, que podem passar os 360 pontos por polegada, acarretou muito mais liberdade para os designers, além dos benefícios em relação à economia das trocas de desenhos na produção, restrita apenas a troca de informações digitais. Com a necessidade de calibração dos perfis, e medição de cores, o uso dos espectrofotômetros é de grande importância para garantir a constância de tonalidade entre períodos de produção, e desenvolvimento de perfis de cor adequados para o desenvolvimento dos projetos.

\subsection{Medição de cor}

Existem alguns tipos de equipamentos para medição de cor, dentre eles estão os colorímetros, densitômetros digitais e os espectrofotômetro. A seguir faz-se uma breve introdução sobre as características desses equipamentos.

\subsubsection{Colorímetro}

Os colorímetros são dispositivos que fazem uso de filtros vermelhos, verdes e azuis que imitam a resposta do olho humano à luz e cor ${ }^{1}$. É amplamente utilizado para controle de qualidade, mede as cargas de tinta nos impressos, demonstrando se está dentro da tolerância setada pelo usuário. Costa e Beltrammi (2013, p. 24) Colorímetros são instrumentos mais simples que permitem a aquisição de cores utilizando três filtros.

\footnotetext{
${ }^{1}$ Disponível em: http://www.xrite.com
} 


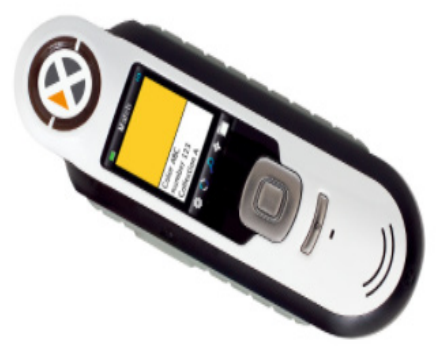

Figura 6 - Colorímetro [[Q1: Q1]]. Fonte: https://engecolornet.com.br/

A colorimetria aplicada e a análise de cores tanto servem para a indústria têxtil digital quanto para a indústria gráfica e cerâmica, que, por sua vez, precisam trabalhar com perfil, ajustes de cores específicas, Pantones, cargas de cores, aplicação de tintas, materiais de impressão e aplicação. (DACOREGIO, 2016, p. 14)

\subsubsection{Densitômetro Digital}

Esse equipamento de acordo com Albuquerque (2012) tem a função de medir a densidade da carga de tinta no impresso. Sobre sua função, Araújo (2012) destaca que é utilizado em aplicações fotográficas para ajustar o tempo de exposição e nos impressos para avaliar o ajuste de nível de tintas.

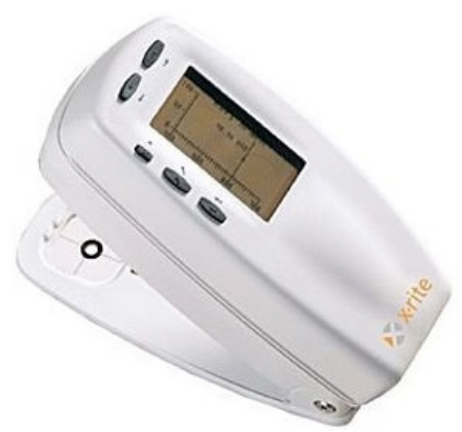

Figura 7 - Densitômetro digital. Fonte: http://sellerink.com.br/blog/ 2010

\subsubsection{Espectrofotômetro}

O espectrofotômetro é um aparelho capaz de medir cargas de todos os instrumentos, sendo mais versátil e preciso que o densitômetro e os colorímetros. (DACOREGIO, 2016)

Murphy (2005) afirma que o espectrofotômetro faz a leitura de intensidade de refração de luz em uma determinada superfície. Ele gera um feixe de luz que após refratado a superfície medida, faz uma coleta de informações com os resultados das cores obtidas. São amplamente utilizados para calibração de monitores e geração de perfis de cor. 


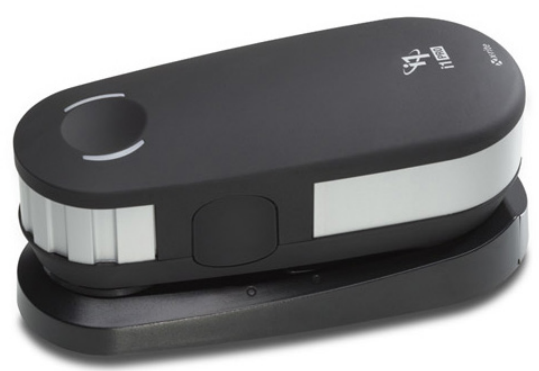

Figura 8 - Espectrofotômetro. Fonte: $<$ https://www.xrite.com/pt-pt/

Sobre a importância do espectrofotômetro, Beltrami e Costa (2013, p. 23) ressaltam que quando usado corretamente este, no fluxo de trabalho digital permite economias de tempo ponderáveis quando a conversão dos dados que contêm a imagem que necessita ser transferida para a impressora digital de cerâmica.

\subsubsection{Criação do perfil de cor}

A transformação na indústria gráfica vem trazendo cada vez mais melhorias no setor, antes utilizava-se nessa área equipamentos com sistemas fechados, atualmente a criação de perfil de cores evoluiu trazendo melhorias.

Dacoregio (2016, p. 28) apud Holdschip (2007) ressaltam que no princípio da evolução digital trabalhava-se com sistemas fechados ou proprietários, utilizados para suprir necessidades de coloração. Portanto, esses dispositivos (impressoras e computadores) usados nos processos eram associados com valores conhecidos, de forma que poderiam trabalhar sempre alinhados. Por serem de alto custo, foi preciso um novo tipo de sistema, mais viável e também mais simples, então foi criado o sistema ICC (Internacional Color Consortium).

Com relação os perfis ICC, em 1993, diferentes companhias como Adobe, Agfa, Apple, Kodak e outras criaram o ICC (International Color Consortium) para encontrar uma forma padrão que solucionasse os problemas na hora de conseguir as cores confiáveis e precisas, para quando se passasse uma imagem por um dispositivo. (KATCHEROFF, 2009)

Desta forma o perfil de criação de cores é indispensável, pois orientam padrões de cores. Freitas destaca que de acordo com a abordagem teórica apresentada, que ao discutir algumas especificidades do processo de criação do design são geradas conexões com o propósito criador com os meios realizadores, assim a matéria e a técnica são inseridos em um momento. (FREITAS, 2012 p. 24)

Ainda, sobre os perfis ICC, Katcheroff (2009, p. 127) ressalta que o ICC desenvolveu uma série de padrões orientados ao tratamento da cor que são indispensáveis de dispositivos concretos.

O principal objetivo desse site para o perfil de criação de cores é tornar possível o tratamento digital das cores, sem que elas sejam afetadas pelas peculiaridades de cada aparelho ou meio. (KATCHEROFF, 2009, p. 127)

Desta forma, a criação de perfil ICC foi necessária, principalmente para empresas que produzem produtos/peças com o mesmo perfil de cores, pois assim as medidas de cores ficam igualadas entre os produtos, garantindo a qualidade.

\section{PROCEDIMENTOS EXPERIMENTAIS}

Esta pesquisa possui relevância social, pois se pretende realizar um estudo de gerenciamento colorimétrico, além dos elementos influenciadores na variação de cor por meio do processo cerâmico, desde a etapa da esmaltação até o final do ciclo de queima. 
Com isso, realiza-se estudo bibliográfico e de campo para concretizar esse objetivo. Consequentemente, por meio do procedimento metodológico, busca-se determinar os métodos e a abordagem da pesquisa, as técnicas que serão utilizadas no decorrer do trabalho, os instrumentos, menciona-se o contexto da pesquisa e seus procedimentos, bem como a população e a amostra. Já que esses procedimentos serão necessários, pois podem levar a uma melhor aplicação da pesquisa e posteriormente a análise de dados. Neste capítulo será aplicado o procedimento experimental descrito no fluxograma da figura 9.

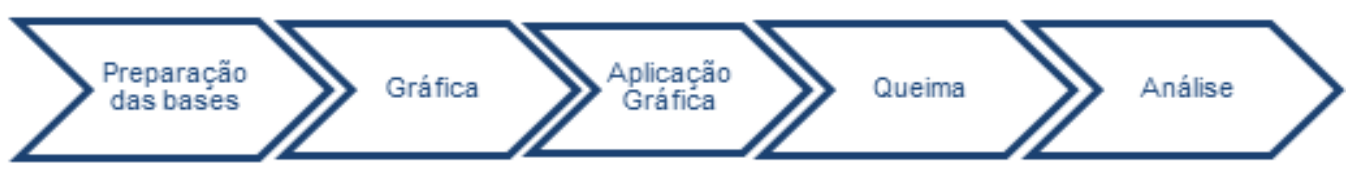

Figura 9- fluxograma de procedimento experimental. Fonte: do autor, 2018

Para que a pesquisa se solidifique, usam-se os métodos científicos para auxiliar no decorrer do trabalho. Quanto à natureza dessa pesquisa, é de caráter aplicado, pois tem a intenção de aliar teoria e prática. (LAKATOS \& MARCONI, 2009)

Referente à abordagem do problema, a pesquisa é de caráter quali-quantitativo, pois tem-se a intenção de descrever a análise e discussão dos resultados, além de usar gráficos para melhor compreensão da pesquisa. Para as autoras Lakatos \& Marconi (2009), a pesquisa apresenta-se como qualitativa porque ao descrever e analisar o estudo feito, leva-se em consideração as características e a análise dos sujeitos que participarão da pesquisa.

Ainda de acordo com as autoras, a pesquisa pode-se apresentar também de forma quantitativa, pois preocupa-se em tabular os dados adquiridos. A metodologia qualitativa preocupa-se em analisar e interpretar aspectos mais profundos, descrevendo a complexidade do comportamento humano. (LAKATOS \& MARCONI, 2009). Como etapa do experimento, destacam-se as seguintes:

Preparação das bases: Na primeira etapa, como demonstrado no fluxograma serão preparadas as bases cerâmicas porcelanato $60 \times 60$ pré queimadas a $900{ }^{\circ} \mathrm{C}$ para conferir dureza nas mesmas, nas quais serão aplicados dois tipos de esmalte com o mesmo tipo de engobe. Aplicados por pistola de pintura em cabine, densidade de 1,55 g/L ideal para forma de aplicação em laboratório, em campo a densidade varia conforme o método de aplicação. Camadas de $250 \mathrm{~g}$ de engobe e $150 \mathrm{~g}$ de esmalte, para ambos os testes, em esmalte brilhante e mate.

Gráfica: Nesta etapa foi desenvolvido o perfil ICC, com esse perfil foram geradas suas cartas teste, por meio do software ilprofiler, da x-rite, com 900 patches de 4 cores. Após a geração da carta teste, a imagem foi importada para o software adobe photoshop, onde foram adicionadas duas fotos: uma colorida e uma preto e branco com variação nos tons de cinza juntamente com uma decomposição das cores CMYK. fig 10 

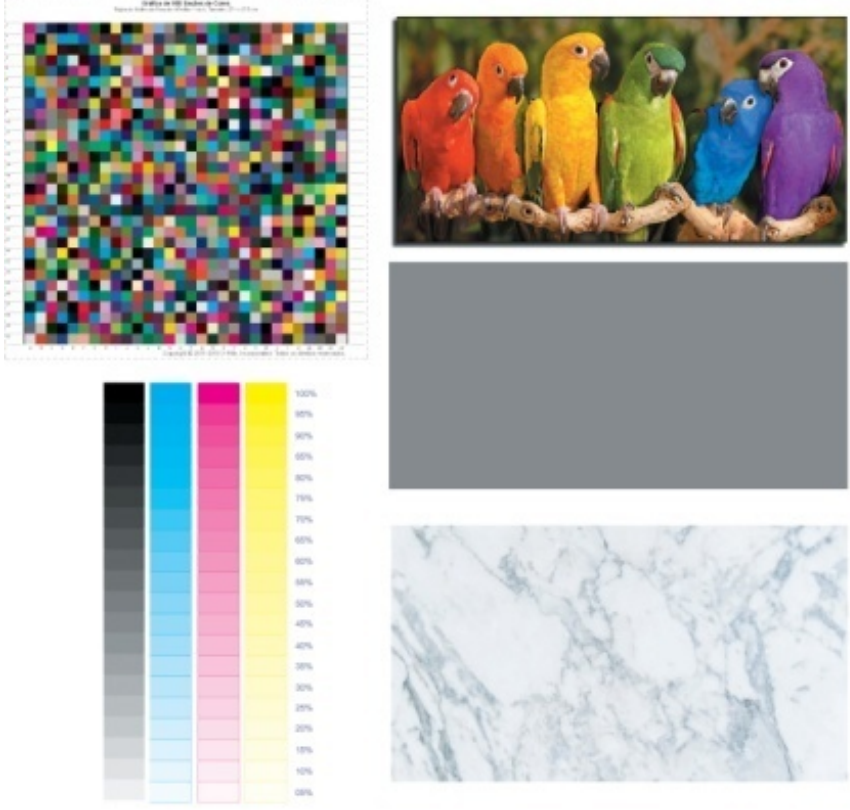

Figura 10 - Gráfica teste. fonte: do autor, 2018

Aplicação Gráfica: impressa a gráfica, por uma impressora digital Kerajet K4 CA40, com 4 cores, azul, marrom, bege e preto, cores mais utilizadas na impressão cerâmica; fig 11.

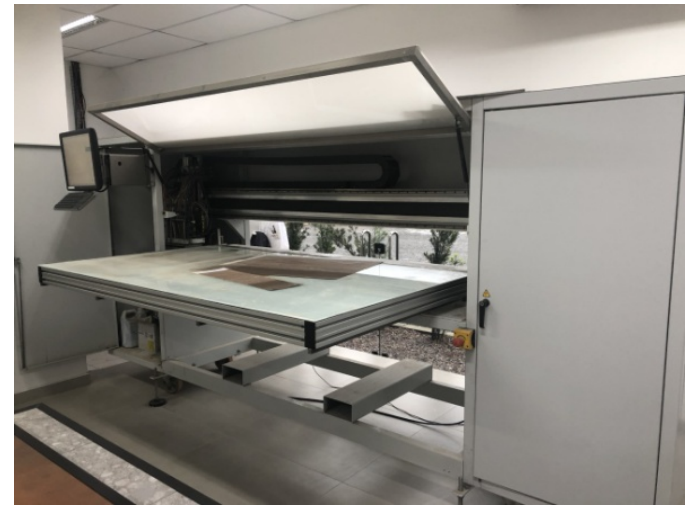

Figura 11 - Kerajet. fonte: do autor, 2018

Queima: após a aplicação da gráfica, as peças foram submetidas a queima em ciclos de 38 e 50 minutos, a 1170 e $1200{ }^{\circ} \mathrm{C}$ célsius em forno industrial de $20 \mathrm{~m}$;

Análise: verificação dos dados obtidos após a queima por meio de espectrofotômetro e analise visual, para posteriores conclusões.

Após a queima da peça, faz-se a leitura dos patches que foram impressos na etapa de aplicação da gráfica, para isso é utilizado o I1pro que é um espectrofotômetro desenvolvido pela X-Rite. Com os dados da leitura, o software Iprofiler gera um arquivo no qual estão relacionadas os percentuais de tintas e os valores colorimétricos alcançados em termos de L, a e b. Na fig. 12 pode ser observado a leitura da carta teste. 


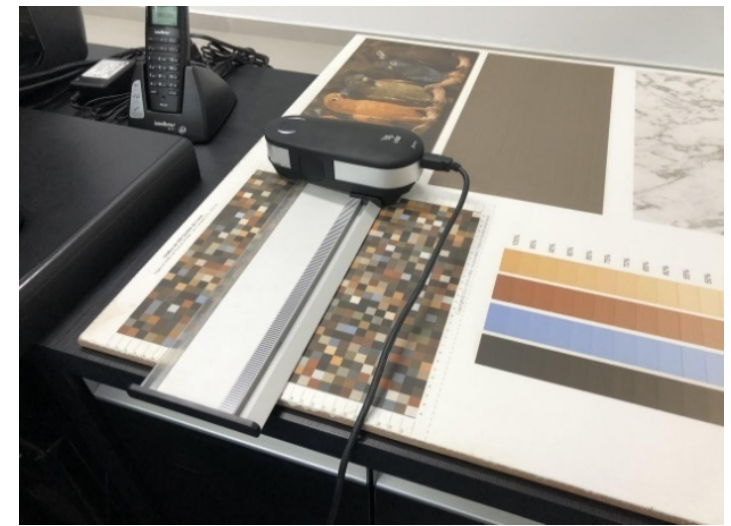

Figura 12 - leitura da carta teste. Fonte: do autor - 2018

\section{ANÁLISE E DISCUSSÃO DOS RESULTADOS}

A análise das provas foi dividida em duas partes: a primeira por meio da leitura dos patchs, desta forma foram coletados os seguintes dados no software I1 profiler: coordenadas representadas por linhas e colunas, a cor no espaço CMYK e L a b, como representado nas tabelas 1 e 2 :

Tabela 1 - Espaços de cor, Esmalte mate $1170{ }^{\circ} \mathrm{C}$

\begin{tabular}{ccccccccc}
\hline Linha & Coluna & C & M & Y & K & L & A & B \\
\hline 1 & 1 & 24,83 & 100,00 & 28,17 & 0 & 42,37 & 20,45 & 26,06 \\
2 & 4 & 88,98 & 22,70 & 0 & 0 & 53,89 & 0,98 & $-10,87$ \\
5 & 22 & 10,37 & 8,80 & 100,00 & 0 & 66,55 & 16,39 & 31,87 \\
13 & 7 & 46,61 & 0 & 50,86 & 100,00 & 27,42 & 6,05 & 9,41 \\
\hline
\end{tabular}

Fonte: do autor, 2018

Tabela 2 - Espaços de cor, Esmalte mate $1200^{\circ} \mathrm{C}$

\begin{tabular}{cccccccccc}
\hline Linha & Coluna & C & M & Y & K & L & A & B \\
\hline 1 & 1 & 24,83 & 100,00 & 28,17 & 0 & 78,70 & 0,43 & 3,13 \\
2 & 4 & 88,98 & 22,70 & 0 & 0 & 46,35 & 0,22 & $-5,24$ \\
5 & 22 & 10,37 & 8,80 & 100,00 & 0 & 59,37 & 12,29 & 30,44 \\
13 & 7 & 46,61 & 0 & 50,86 & 100,00 & 27,14 & 3,25 & 5,69 \\
\hline
\end{tabular}

Fonte: do autor, 2018.

Entre os esmaltes mate e brilhante não foram constatadas alterações de tonalidade significativas. Com a variação de temperatura ouve significativas diferenças, como pode ser identificado no gráfico gerado pelo Ilprofiler, onde representado na cor vermelha a temperatura de $1170{ }^{\circ} \mathrm{C}$ e na cor azul a temperatura de $1200^{\circ} \mathrm{C}$. fig 13 


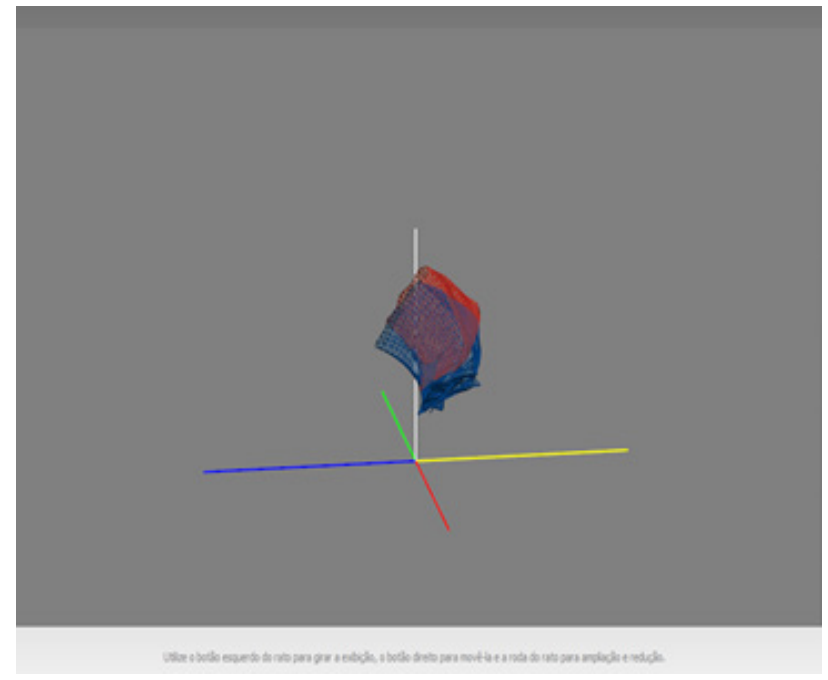

Figura 13 - Gráfica comparativo temperaturas $1170^{\circ} \mathrm{C}$ e $1200^{\circ}$. Fonte: do autor, 2018.

Na segunda parte foi executada uma análise visual onde foram avaliadas as provas: $1170{ }^{\circ} \mathrm{C}$ com esmaltes mate e brilhante observadas nas fig 14. e fig 15.

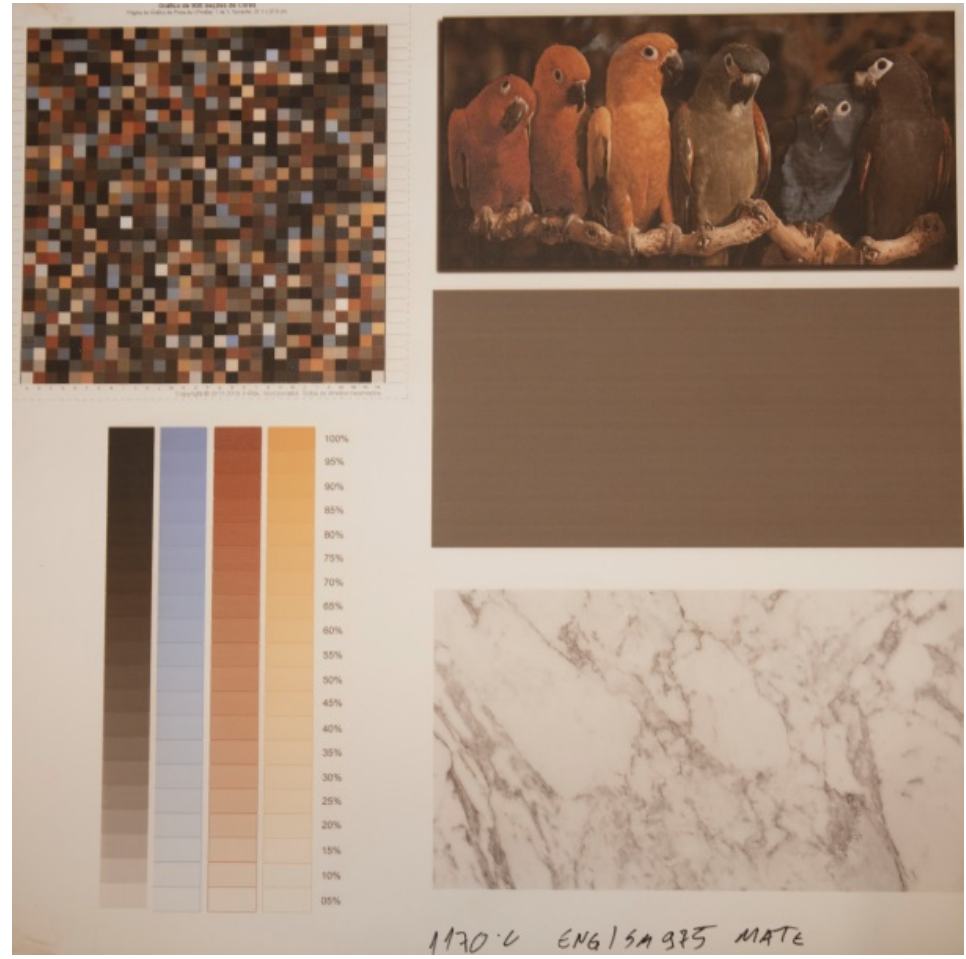

Figura $14-$ Teste $1170{ }^{\circ} \mathrm{C}$ esmalte mate. Fonte: do autor, 2018. 


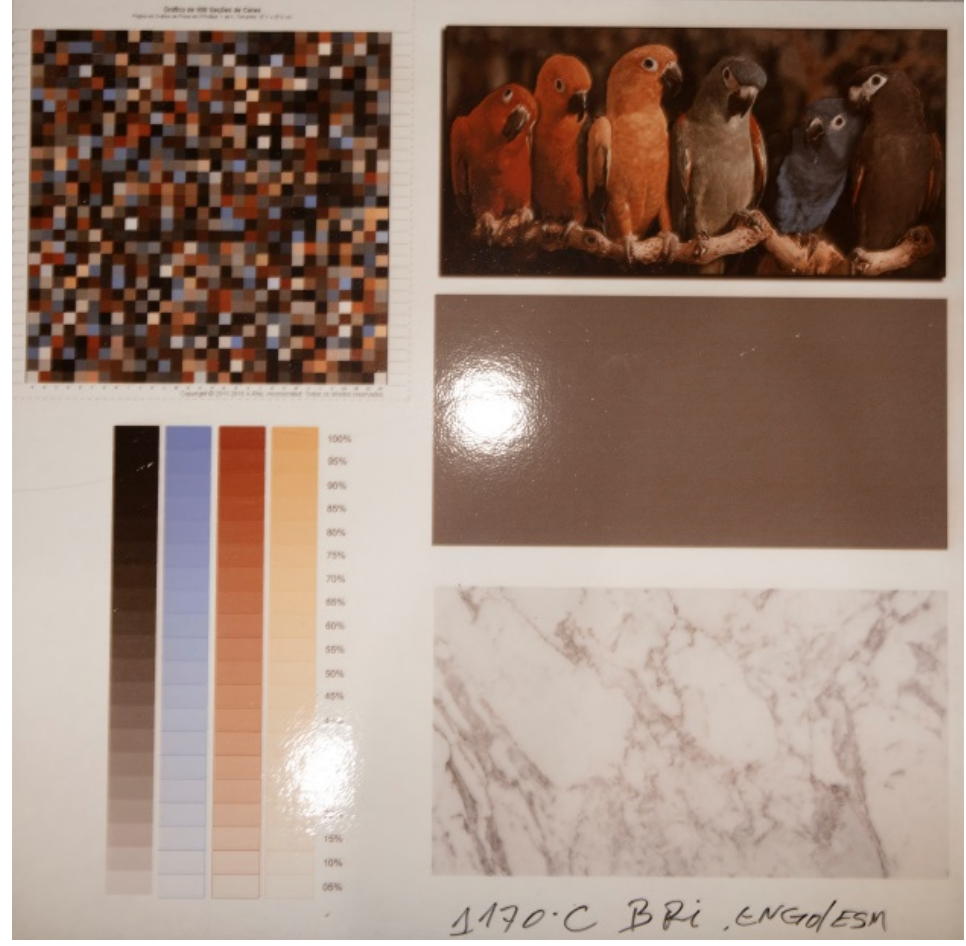

Figura 15 - Teste $1170{ }^{\circ} \mathrm{C}$ esmalte brilhante. Fonte: do autor, 2018.

No comparativo das fig. 14 e fig. 15, não são encontradas diferenças de tonalidade significativas, nota-se apenas que na situação brilhante as cores ficam mais intensas, e com brilho, o que é característica do esmalte em questão. $\mathrm{Na}$ análise seguinte o mesmo teste foi repetido em uma temperatura de $1200{ }^{\circ} \mathrm{C}$, e os resultados podem ser observados nas fig. 16 e fig. 17.

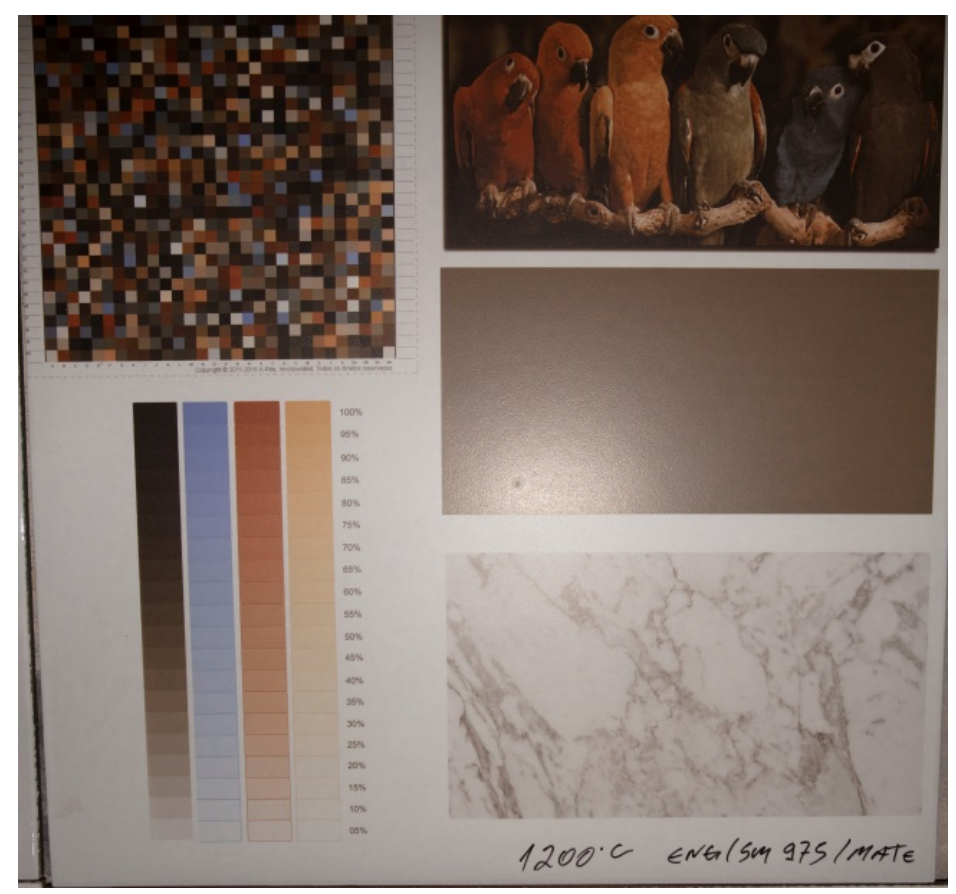

Figura 16 - Teste $1200{ }^{\circ} \mathrm{C}$ esmalte mate. Fonte: do autor, 2018. 


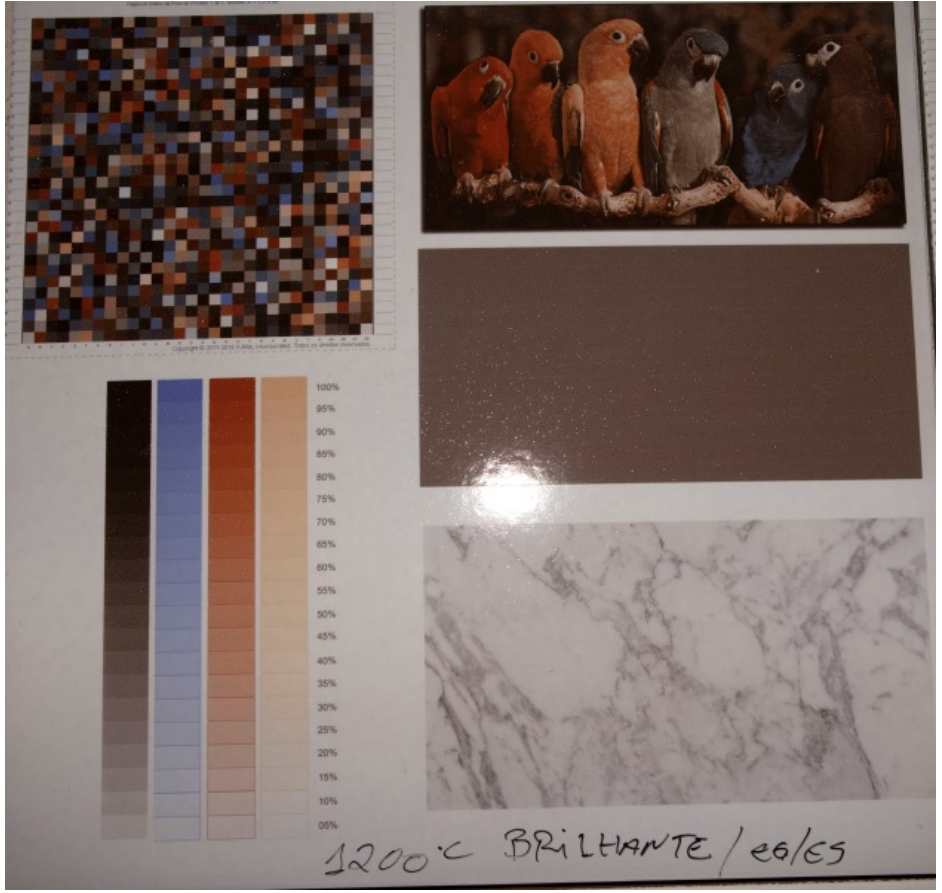

Figura 17 - Teste $1200{ }^{\circ} \mathrm{C}$ esmalte brilhante. Fonte: do autor, 2018 .

Nos testes na temperatura de $1200{ }^{\circ} \mathrm{C}$, não são encontradas diferenças entre os dois tipos de esmalte, porém se comparadas as fig. 15 e fig. 17 (esmalte brilhante) nota-se a influência da diferença de temperatura. Na qual com maior temperatura de queima acontece à predominância da tonalidade azul, já na temperatura menor a predominância do tom bege-amarelado, que pode ser vista nos casos do esmalte mate fig. 14 e fig. 16.

Os testes foram executados afim de determinar os agentes causadores da variação tonal durante o processo de fabricação de revestimentos cerâmicos, neles as mudanças mais significativas encontradas foram na variação de temperatura, o que produziu resultados semelhantes entre os casos analisados. Durante a etapa de queima podem ocorrer variações de temperatura, devido a problemas técnicos nas zonas de queima do forno, ou ajustes operacionais para garantir o formato das placas cerâmicas, o que pode acarretar esse tipo de variação de cor.

\section{CONSIDERAÇÕES FINAIS}

Com o término desse trabalho, nota-se que o gerenciamento colorimétrico nas peças de revestimento cerâmico é de extrema relevância para se almejar a qualidade do produto, conseguindo-se concretizar o objetivo principal do artigo. Identificou-se também que o projeto é uma excelente linha de pesquisa e pode ser ainda mais aprofundado, pois esse tema vem sendo pouco desenvolvido em livros e umas das dificuldades encontradas no decorrer dessa pesquisa foi à falta de bibliográfica sobre o assunto. Com isso alguns pontos podem ser destacados:

- A temperatura é um agente causador de variação tonal. Em temperatura de $1200^{\circ} \mathrm{C}$, há predominância dos tons azuis e entre 1170 e $1200{ }^{\circ} \mathrm{C}$ os tons predominantes são os beges;

- Entre os esmaltes mate e brilhante de composição semelhante não há variações significativas em relação a tonalidade;

- O gerenciamento evita a abertura lotes de produtos, por manter a constância tonal. Esses lotes são abertos quando há alguma alteração na tonalidade das peças, mas que não comprometem de todo o design, assim o fabricante cria uma nova classificação para o produto, comumente chamado na cerâmica de "abrir um novo tom". 
- Também pode ser constatado que, com o gerenciamento correto, facilita o trabalho do designer, com acerto de cores;

Assim, o trabalho de um designer é necessário para essa área da empresa, pois pode acarretar para a empresa um grande investimento, almejando bons resultados. Assim, sob essa perspectiva, Freitas destaca que (2012, p. 783) O designer de superfície tem a função de tratar, explorar e ressaltar, a interface comunicativa dos objetos, unindo características funcionais e estéticas que se apresentam também em outras especialidades.

Cada empresa cerâmica tem um fluxo específico de trabalho em seu desenvolvimento, possuem esmaltes específicos, tintas diferentes, e temperaturas de operação distintas, por isso esse estudo pode servir como fundamentação teórica para que cada empresa pesquise como seu produto reage a diferentes condições, e faça o gerenciamento adequado. $\mathrm{O}$ estudo foi desenvolvido utilizando esmalte e engobe, mas nada impede de utilizar a mesma metodologia de pesquisa para aplicação em outro tipo de substrato, com aplicação de outros tipos de esmalte, como os acetinados e esmaltobe.

\section{Referências}

ABCERAM. Informações técnicas - processos de fabricação, Associação Brasileira de Cerâmica. Disponível em https://abceram.org.br/processo-de-fabricacao/. Acesso: 14 maio 2018.

ABRIL FILHO, Oscar de. Esmaltes, Esmaltação e Variação de Tonalidade. Cerâmica Industrial, Estiva Gerbi, v. 1-6, n. 4, p.40-42, dez. 1999. Disponível em: <http://www.ceramicaindustrial.org.br/pdf/v04n16/v4n16_8.pdf>. Acesso em: 04 maio 2018.

AMBROSE, Gavin; HARRIS, Paul. Cor. Rio Grande do Sul: Bookman, 2009.

ARAUJO, Arnaldo de Albuquerque; LEÃO, Alexandre Cruz; SOUZA, Luiz Antônio Cruz; Implementação de Sistema de Gerenciamento de Cores para Imagens Digitais. Disponível em: (http://laplace.dcc.ufmg.br/npdi/uploads/c0a80a68be44-f8bb.pdf)

BELTRAMI, Alessandro; COSTA, Maíra da. A Medição das Cores em Cerâmica Digital. Cerâmica Industrial, [s.I.], v. 18, n. 2, p.23-25, 2013. Editora Cubo Multimidia. http://dx.doi.org/10.4322/cerind.2014.040.

BOSCHI, Anselmo Ortega et al. A DECORAÇÃO DE REVESTIMENTOS CERÂMICOS POR IMPRESSÃO DIGITAL (JATO DE TINTA). In: CONGRESSO BRASILEIRO DE CERÂMICA, 60., 2016, Águas de Lindóia. Anais... . Águas de Lindóia: Congresso Brasileiro de Cerâmica, 2016. p. 757 - 768.

BOSCHI, Anselmo; MELCHIADES, Fábio G. Cores e Tonalidades em Revestimentos Cerâmicos. 1999. 8 f. Dissertação (Mestrado) - Curso de Cerâmica Industrial, Laboratório de Revestimentos Cerâmicos, Ufscar, São Carlos, 1999.

BUENO, Mike. A cor e a visão humana. 2015. Disponível em: <http://www.mikebueno.com.br/arquivos/A_Cor_e_a_Visao_Humana_-_por_Mike_Bueno.pdf>. Acesso em: 09 abr. 2018.

CABEDO, Javier; ZARAGOZA, Jesús; CANÓS, P. Corma. Como a Cadeia Pesquisa, Desenvolvimento e Inovação (PDI) Tornou Possível a Decoração por Jato de Tinta. Cerâmica Industrial, [s.I.], v. 19, n. 3, p.7-12, 2014. Editora Cubo Multimidia. http://dx.doi.org/10.4322/cerind.2014.072.

CERÁMICA, Instituto de Tecnologia. Decoração Cerâmica com Tecnologias de Jato de Tinta (Inkjet): $2^{a}$ Parte. Cerâmica Industrial, [s.I.], v. 17, n. 2, p.7-14, 2012. Editora Cubo Multimidia. http://dx.doi.org/10.4322/cerind.2014.006.

CLAUSELL, J. J.; ORTIZ, L.; MIRA, J.. Design Cerâmico Adaptado à Impressão Digital. Cerâmica Industrial, [s.I.], v. 17, n. 3, p.7-14, 2012. Editora Cubo Multimidia. http://dx.doi.org/10.4322/cerind.2014.013.

CRISTIANO, M. NANDI, V.S. ZACCARON, A. Evolução do processo de decoração na indústria de revestimentos cerâmicos: impressão jato de tinta. In Revista Cerâmica. São Paulo, 2015. Disponível em Acesso em: 10 de mai, 2018.

DACOREGIO, Lethyéri Tenfen. gerenciamento colorimétrico aplicado em sublimação têxtil: como entender a indústria têxtil por meio das cores. SATC, Criciúma, 2016

DAL BÓ, Marcelo; Efeito das propriedades dos esmaltes e engobes sobre a curvatura de revestimentos cerâmicos. Universidade Federal de Santa Catarina UFSC. 2012. Disponivel em http://www.scielo.br/pdf/ce/v58n345/19.pdf. Acesso em: 14 de maio. 2018

FERRARI, Kátia R. et al. Transformações das Matérias-Primas do Suporte Durante a Queima de Revestimento Cerâmico. Cerâmica Industrial, São Carlos, v. 2, n. 5, p.53-58, abr. 2000. Disponível em: <http://www.ceramicaindustrial.org.br/pdf/v05n02/v5n2_7.pdf>. Acesso em: 04 maio 2018.

FLORES, Ana. 0 que são vidrados. 2018. Disponível em: <http://www.ufrgs.br/lacad/revestvidrado.html>. Acesso em: 04 maio 2018.

FRASER, Bruce; MURPHY, Chris; BUNTING, Fred. Real world color management. 2. ed. Berkeley, EUA: Peachit, 2005. 
HUTCHINGS, Ian. Impressão Jato de Tinta para Decoração de Revestimentos Cerâmicos: Tecnologia e Oportunidades. Cerâmica Industrial, [s. L.], v. 15, n. 2, p.7-14, mar. 2010. Disponível em: <http://www.ceramicaindustrial.org. $\mathrm{br} / \mathrm{pdf} / \mathrm{v} 15 \mathrm{n} 2 / \mathrm{v} 15 \mathrm{n} 2 \mathrm{a} 01 . \mathrm{pdf}>$. Acesso em: 10 maio 2018.

KATCHEROFF, Pablo. Coleção Designer Gráfico. Tradução Daniela Oliveira e Marcelle Barros Soares. São Paulo. Digerati Books, 2009.

LAKATOS, Eva Maria; MARCONI, Marina de Andrade; Fundamentos de Metodologia científica. $7^{\text {a }}$ edição - São Paulo: Atlas 2010.

LEÃO, Alexandre Cruz. GERENCIAMENTO DE CORES PARA IMAGENS DIGITAIS. 2005. 135 f. Dissertação (Mestrado) Curso de Mestrado em Artes Visuais, Universidade Federal de Minas Gerais, Belo Horizonte, 2005. Disponível em: $<$ http://www.bibliotecadigital.ufmg.br/dspace/bitstream/handle/1843/JSSS7XGFG3/dissertacao_alexandre_leao.pdf?sequence=1>. Acesso em: 11 maio 2018.

LOPES, André Borges et al. Impressão Digital: A tecnologia a serviço da comunicação. São Paulo: Abigraf, . 323 p

LOPES, L. C. Fundamentos da Colorimetria. 2009. 40 f. Tese (Doutorado) - Curso de Design, Puc, Rio de Janeiro, 2010. Disponível em: <http://www2.dbd.pucrio.br/pergamum/tesesabertas/0621484_09_cap_02.pdf>. Acesso em: 11 maio. 2018.

MELCHIADES, Fábio G.; BOSCHI, Anselmo O. Cores e Tonalidades em Revestimentos Cerâmicos. Cerâmica Industrial, [s. L.], v. 2, n. 1-6, p.11-18, dez. 1999. Disponível em: <http://www.ceramicaindustrial.org.br/pdf/v04n16/v4n16_2.pdf>. Acesso em: 11 maio 2018.

MORTARA, Bruno. Impressão Digital: introdução e tecnologia. São Paulo: Scortecci, 2009. 75 p.

NEWTON, Isaac. A nova teoria sobre Luz e Cores. 1672. Disponível em: <http://www.sbfisica.org.br/rbef/pdf/v18a33.pdf>. Acesso em: 09 abr. 2018.

PEDROSA, Israel. O universo da Cor. Rio de Janeiro Senac: 2003.

RADO, Paul. Introdução à tecnologia cerámica. 2 ed. Worcester: Omega, 1990. 322 p.

RAULINO, Francieli Comin. AFIRMAÇÃO DA BRASILIDADE POR MEIO DO REVESTIMENTO CERÂMICO: A CULTURA FREVO COMO ELEMENTO DE DESIGN E DIFERENCIAÇÃO ESTÉTICA. 2012. 95 f. TCC (Graduação) - Curso de Design Gráfico, Satc, Criciuma, 2012.

REIG, Yolanda et al. Decoração Cerâmica com Tecnologias de Jato de Tinta (Inkjet). Cerâmica Industrial, [s.I.], v. 17, n. 1, p.20-28, 2012. Editora Cubo Multimidia. http://dx.doi.org/10.4322/cerind.2014.003.

VANDERLIND, Guilherme Espindola; FARACO, Morgana Nuernberg Sartor. Decoração digital na cerâmica: um estudo sobre o desenvolvimento de cor, perfil, espaço colorimétrico e matérias-primas. 2017. 24 f. TCC (Graduação) Curso de Engenharia Química, Satc, Criciuma, 2017.

YAMANE, Laura Ayako. Estamparia têxtil. 2008. 124 f. Dissertação (Mestrado) - Curso de Poéticas Visuais, Usp, São Paulo, 2008. 